Tijana S. Vesić Pavlović ${ }^{*}$

https://doi.org/10.18485/analiff.2020.32.2.9

Univerzitet u Beogradu

$811.111^{\prime} 42$

Mašinski fakultet

Originalni naučni rad

Danijela D. Đorđević

Primljen: 10.07.2020

Univerzitet u Beogradu

Prihvaćen: 18.011.2020

Poljoprivredni fakultet

\title{
UPOTREBA OGRADA I POJAČIVAČA U STUDENTSKIM ESEJIMA O ZAŠTITI ŽIVOTNE SREDINE NA ENGLESKOM JEZIKU
}

\begin{abstract}
Poslednjih godina, upotreba metadiskursa u pisanoj produkciji na univerzitetskom nivou učenja jezika predstavlja vrlo važnu temu u literaturi. Ovaj rad bavi se upotrebom dve specifične metadiskursne odlike, ograda i pojačivača, u esejima studenata posvećenim pitanjima sprečavanja efekata globalnog zagrevanja i napisanim u okviru kursa engleskog jezika na univerzitetskom nivou. Analizirano je ukupno 124 eseja (20.829 reči). Primenom Hajlandovog interpersonalnog modela metadiskursa, utvrđeno je da se u analiziranim esejima znatno češće koriste ograde nego pojačivači (22,23 prema 8,26 na 1000 reči). Unutar obe klase uočavaju se različiti glagolski, imenički, priloški i pridevski markeri ograđivanja i pojačavanja iskaza. U zaključku se ukazuje na neophodnost uvođenja metadiskursnih markera u kurikulum nastave stranog jezika na univerzitetskom nivou s obzirom na njihov značaj ne samo u akademskim, već i u drugim tipovima tekstova s kojima će se (diplomirani) studenti susretati u toku i posle studiranja.
\end{abstract}

Ključne reči: metadiskurs, ograde, pojačivači, studentski eseji, engleski jezik.

\section{Uvod}

U novije vreme, u lingvističkim istraživanjima velika pažnja posvećuje se fenomenu metadiskursa. Ovaj pojam veoma je složen i uprkos tome što su se brojni jezički stručnjaci bavili i bave se ovom temom, ne postoji jedna sveobuhvatna definicija metadiskursa, kao ni opšteprihvaćeni model klasifikacije metadiskursnih markera, o čemu postoje brojne rasprave u literaturi (Ceković-Rakonjac, 2011; Hyland, 2017). No, većina

*_tvesic@mas.bg.ac.rs 
stručnjaka se slaže s tim da se pod metadiskursom podrazumeva „niz sredstava koja autori koriste kako bi eksplicitno organizovali tekst, angažovali čitaoca i naglasili svoje stavove kako prema materijalu, tako i prema publici“ (Hyland \& Tse, 2004: 156).

Opšta razmatranja o značaju upotrebe metadiskursa i brojne analize njegove konkretne upotrebe $\mathrm{u}$ akademskom pisanju podstakla su i mnoga istraživanja upotrebe metadiskursnih markera $\mathrm{u}$ pisanoj produkciji onih koji uče strane jezike na različitim nivoima školovanja, naročito kao sastavni deo i odraz njihove pragmatičke kompetencije (npr. Cheng \& Steffensen, 1996; Fraser, 2010; Hyland \& Tse, 2004; Intaraprawat \& Steffensen, 1995; Li \& Wharton, 2012; Yang \& Sun, 2012), kao i studije o tome u kojoj meri se u nastavnom procesu može podučavati i podsticati pravilna upotreba metadiskursnih markera (npr. Fraser, 2010; Hyland, 2005; Steffensen \& Cheng, 1996).

Imajući u vidu važnost ove teme, ovaj rad bavi se upotrebom dve specifične metadiskursne odlike, ograda i pojačivača, u esejima studenata posvećenim pitanjima sprečavanja efekata globalnog zagrevanja napisanim u okviru kursa engleskog jezika na univerzitetskom nivou. Cilj je bio da se kvantitativno i kvalitativno analizira upotreba ova dva tipa metadiskursnih markera u datom korpusu eseja i da se steknu određeni uvidi u to kakva je trenutna sposobnost studenata da koriste ograde i pojačivače $\mathrm{u}$ argumentativnom eseju na engleskom jeziku. Dodatno, želeli smo da na našem uzorku proverimo rezultate ranijih istraživanja o tome da studenti znatno više koriste ograde od pojačivača.

U drugom odeljku, koji sledi, najpre se podrobnije osvrćemo na pojmove ograde i pojačivača u različitim modelima metadiskursa i na Hajlandove definicije ova dva tipa markera na koje se oslanjamo u radu, a zatim predstavljamo ranija istraživanja posvećena upotrebi ovih metadiskursnih markera u naučnim radovima i esejima. U trećem odeljku opisujemo korpus na kome je sprovedeno istraživanje i primenjenu metodologiju. Četvrti odeljak sadrži rezultate analize, dok se u petom daju zaključna razmatranja i preporuke za buduća istraživanja u ovoj oblasti.

\section{Teorijski okvir istraživanja}

\subsection{Pojam ograda i pojačivača}

Termini "ograda" i "pojačivač" često se javljaju u različitim modelima klasifikacije metadiskursnih markera. Međutim, različiti istraži- 
vači ove termine u većoj ili manjoj meri različito definišu (npr. Holmes, 1982, 1988, 1990; Vande Kopple, 1985; Crismore, Markkanen et al., 1993; Hyland, 2005). Takođe, koriste se i drugačiji nazivi za ove vrste markera, ali, kada se pogledaju primeri koje autori navode, možemo zaključiti da se zapravo radi o istom pojmovnom sadržaju koji u ovom radu označavamo kao ograde i pojačivače.

Različite definicije koje se javljaju u ranijim radovima osvetljavaju različite aspekte onoga šta sve može da se podrazumeva pod terminom ograda. Autor koji je uveo pojam ograde u lingvistiku jeste Džordž Lejkof (Lakoff, 1973), koji ih je opisao kao reči ,čiji je posao da stvari učine više neodređenim ili manje neodređenim" (Lakoff, 1973: 471). Oslanjajući se uglavnom na teoriju prototipa i teoriju rasplinutih skupova, Lejkof je ukazao na to da su ograde veoma značajne u komunikaciji pošto omogućavaju gradijentnost - da nije sve da ili ne, crno ili belo, 0 ili 1, u ili izvan skupa (Lakoff, 1973), kao i na to da ograde omogućavaju iskazivanje nijansi u značenju. Lejkofov spisak ograda sadrži lekseme koje će u budućim istraživanjima lingvisti svrstavati kao ograde, ali i u neke druge grupe, na primer, pojačivače.

Sledeća autorka koja se bavila ovim pojmom jeste Holms (Holmes, 1982: 18; Holmes 1984: 346-347). Ona naporedo koristi termine ograda (engl. hedge) i ublaživač (engl. downtoner). Holms (Holmes, 1988) ograde definiše kao sredstva kojima se ublažava ilokuciona snaga iskaza (na primer, a bit of, you know, kind of, in a way), odnosno, kojima se izražava sumnja. Drugi autori (Crismore, 1983: 14) smatraju da se ogradama pokazuje stepen nesigurnosti (na primer, perhaps, probably, it would seem), odnosno, da ograde (npr. can, could, may, might) predstavljaju jezičke jedinice kojima se pokazuje autorov „nedostatak opredeljenja prema istinitosnoj vrednosti cele propozicije" (Crismore et al., 1993: 50).

Kod jedne klasifikacije metadiskursnih markera koju daje Vande Kople, u okviru markera validnosti kojima se „ocenjuje verovatnoća ili istinitost propozicionog sadržaja" (Vande Kopple, 1985: 84), izdvajaju se i ograde kao markeri koji odražavaju nivo neophodne sumnje (na primer, perhaps, may, might, seem, to a certain extent). U okviru jedne druge klasifikacije, u okviru grupe epistemoloških markera, Vande Kople (Vande Kopple, 2012: 39-40) navodi primere poput it is possible that i perhaps koje naziva terminom štitovi (engl. shields), definišući ih kao opredeljenost ,prema istinitosti ideacionog materijala” (Vande Kopple, 2012: 39). 
Razmatranja o pojmu pojačivača takođe nalazimo kod različitih autora. Holms (Holmes 1982: 18; Holmes 1984: 346-347) pojačivače definiše kao jezička sredstva kojima se pojačava ilokuciona snaga iskaza (na primer, My God, such, really, amazingly), odnosno, kojima se izražava sigurnost (Holmes, 1988). Drugi autori naglašavaju da se pojačivačima (na primer, of course, true, in fact) ukazuje na stepen sigurnosti (Crismore, 1983: 14), kao i da kod ovog tipa markera (na primer, certainly, I know) možemo govoriti o ,stepenu autorovog opredeljenja prema istinitosnoj vrednosti propozicije" (Crismore et al., 1993: 52). Vande Kople (Vande Kopple, 1985, 2012) za pojačivače koristi termin naglašavači (engl. emphatics) i oslanja se na definiciju Vilijamsa da ovaj tip markera ,podvlači ono u šta mi stvarno verujemo - ili bismo želeli da naš čitalac misli da mi verujemo" (Williams 1981: 49 u Vande Kopple 1985: 84).

U ovom radu, odlučili smo za široko korišćen interpersonalni model metadiskursa koji je razvio Ken Hajland (Hyland, 2005: 48-54). Prema Hajlandovom modelu, izdvajaju se dve široke grupe metadiskursnih markera: interaktivni (tranzicioni markeri, okvirni markeri, endoforični markeri, evidencijali, objašnjivači) i interakcioni metadiskursni markeri (ograde, pojačivači, markeri stava, markeri angažovanja, markeri ličnog upućivanja). Kao što se može videti, ograde i pojačivači svrstani su u grupu interakcionih metadiskursnih markera kojima se pokazuje autorov stav prema propoziciji, te mogu uticati na čitaočevu ocenu teksta.

Hajland ograde definiše kao jezička sredstva kojima se izražava suzdržanost (npr. might, perhaps, possible, about) (Hyland, 2005: 49), kao i moguće razmišljanje pisca, pre nego određeno znanje (Hyland, 2005: 52). Drugim rečima, Hajland ističe da su ograde sredstva koja ukazuju na autorovu odluku da poštuje i druga stanovišta, subjektivnost stava da se podatak predstavi kao mišljenje, što može ostaviti prostora za pregovaranje (Hyland, 1998). S druge strane, terminom pojačivač označavaju se sredstva koja piscu služe da naglasi svoju sigurnost (npr. in fact, definitely, it is clear that) (Hyland, 2005: 49), kao i da pojača svoje argumente (Hyland, 2005: 53). To znači da, iako postoje različita mišljenja i stavovi, autor pojačivačima naglašava da u konkretnom slučaju nema mesta pregovaranju - autor koristi samouveren ton da iskaže svoje tvrdnje (Hyland, 2005: 53).

Ako u obzir uzmemo formalne kriterijume, možemo reći da se za ograđivanje, odnosno, pojačavanje iskaza najčešće koriste sledeće gramatičke klase/vrste reči - glagoli (modalni glagoli i leksički glagoli), adver- 
bijali, imenice i pridevi (npr. Holmes, 1982, 1988). Vrste reči koje se upotrebljavaju u funkciji ograda ili pojačivača mogu da variraju u zavisnosti od jezika. Na primer, u jednom istraživanju se pokazalo da se epistemički modalni markeri (epistemički pomoćni glagoli, epistemički leksički glagoli, epistemički pridevi, epistemički prilozi i epistemičke imenice) češće koriste kao ograde u naučnim radovima na engleskom nego u naučnim radovima na srpskom jeziku (Đorđević, 2017a). Takođe, upotreba priloških ograda češća je u naučnim radovima na engleskom jeziku nego u onima na srpskom (Đorđević, 2015).

Ranija istraživanja ograda i pojačivača u naučnom diskursu govore da njihova upotreba u člancima pisanim na dva različita jezika, engleskom i kineskom, može biti i kulturno uslovljena - na primer, u radovima na engleskom jeziku koristi se više ograda nego u radovima na kineskom, dok je broj pojačivača veći u radovima pisanim na kineskom (Hu \& Cao, 2011). Đorđević (2017b) utvrđuje da se u slučaju naučnih radovima iz različitih naučnih disciplina na engleskom i srpskom jeziku ograde više upotrebljavaju u engleskim nego u srpskim naučnim radovima, bez obzira na disciplinu. Ovaj nalaz bi se mogao potkrepiti kulturološkim razlikama, različitim pravilima koja autori moraju da ispoštuju prilikom pisanja radova, ali i različitim mogućnostima upotrebe jezičkih jedinica koje se koriste za ograđivanje.

\subsection{Ranija istraživanja o upotrebi ograda i pojačivača u esejima neizvornih govornika engleskog jezika}

Akademsko pisanje predstavlja sastavni deo razvijanja jezičkih veština kod onih koji uče strani jezik, a može biti posebno korisno za studente koji uče jezik na univerzitetskom nivou, jer im može pomoći u njihovoj budućoj struci (npr. Blagojević, 2008; Fraser, 2010; Hyland, 2005). Razvijanje svesti o pravilnoj upotrebi metadiskursnih markera iskristalisalo se kao veoma važno pitanje, pre svega u nastavi pisanja na stranom jeziku. U analizi frekvencije i uspešnosti u upotrebi metadiskursa u eseju svakako je važan faktor i prethodno znanje o ovim odlikama jezika i njihovo uvođenje u nastavni proces, na šta su ukazivale i prethodne studije, koje obiluju preporukama da se metadiskursni markeri direktno podučavaju na nivou srednje škole i ranih faza obrazovanja na univerzitetskom nivou (npr. Ho \& Li, 2018; Intaraprawat \& Steffensen, 1995; Lee \& Casal, 2014).

Postoji veći broj istraživanja koja su se bavila upotrebom metadiskursnih markera u esejima studenata na univerzitetskom nivou školova- 
nja. Ho i Li (Ho \& Li, 2018) koristeći uzorak eseja na engleskom jeziku studenata prve godine univerziteta zaključuju da studenti nisu baš vični u korišćenju metadiskursnih markera kako bi izgradili konstruktivne argumente. Frekvencija upotrebe metadiskursih markera može da zavisi i od kvaliteta samog eseja; naime, pokazuje se da bolje ocenjeni eseji sadrže više metadiskursnih markera od lošije ocenjenih, što može ukazivati na to da su oni koji su ih pisali svesniji svoje publike, da umeju objektivnije da sagledaju ono što pišu i da to na različite načine prokomentarišu (Intaraprawat \& Steffensen, 1995: 256).

Ranija istraživanja upotrebe metadiskursnih markera u studentskim esejima pokazala su da se ograde koriste u znatno većoj meri nego pojačivači (Crompton, 2012; Lee \& Deakin, 2016). Kvalitetniji eseji sadrže više ograda (Lee \& Deakin, 2016), a po tipovima ograda u jednom istraživanju pokazalo se da se više upotrebljavaju modalni glagoli i prilozi nego leksički glagoli i pridevi (Crompton, 2012). Ako se pogleda struktura eseja, ograde se najmanje koriste u zaključku, a pojačivači najviše, što može da ukazuje na to da studenti u delu zaključka osećaju najviše slobode da esej završe ,jačim tvrdnjama koje govore u prilog stavu koji su zastupali u prethodnim pasusima" (Ho \& Li, 2018: 58).

Hajlandovo istraživanje (Hyland, 2000) o tome koliko studenti koji uče engleski jezik umeju da prepoznaju ograde i pojačivače u akademskom tekstu, kao i njihovu ulogu, pokazalo je da studenti više primećuju pojačivače i u većoj meri razumeju njihov uticaj na stavove iznete u tekstu. U znatno manjoj meri umeju da uoče ograde i njihov efekat na tekst, tj. najčešće uopšte ne mogu da prepoznaju kada je ograda upotrebljena ili im pripisuju neodgovarajući nivo sigurnosti koji iskazuju (Hyland, 2000).

\section{Korpus i metodologija istraživanja}

Istraživanje je sprovedeno u toku prvog semestra školske 2019/2020. godine, u okviru časova engleskog jezika na prvoj godini studija na Mašinskom fakultetu Univerziteta u Beogradu. Studenti su dobili zadatak da najpre pročitaju adaptirani tekst na engleskom jeziku o pet stvari/zakletvi (engl. pledges) koje bi mogle da se sprovedu u delo kako bi se pomerio datum Dana ekološkog deficita (engl. Earth Overshoot Day), o kome su na prethodnim časovima takođe čitali. Zakletve su se odnosile na mogućnost da se jedan dan nedeljno ne jede meso, da se smanji potrošnja energije u domaćinstvu, da se do posla/fakulteta putuje javnim prevozom umesto 
samostalno u vozilu, da se smanji rasipanje hrane na dnevnom nivou i da se smanji upotreba papira. Zatim se od studenata tražilo da na osnovu pročitanih zakletvi iskažu svoje mišljenje o tome koju od ovih zakletvi bi bilo najteže ili najlakše ispuniti, za njih lično i uopšteno gledano. Naglašeno je da treba da obrazlože svoje mišljenje u okvirno 150 reči. Specifičnost zadatka ogledala se u tome što su studenti radili u timu, sačinjenom od dva ili tri člana, pa je svrha zadatka osim uvežbavanja pisanja argumentativnog eseja na engleskom jeziku bila i da provežbaju svoje veštine timskog rada i izražavanja grupnog mišljenja. Studenti su imali dva školska časa na raspolaganju za ovaj zadatak, u okviru redovne nastave engleskog jezika na fakultetu. Dobijeno je ukupno 124 eseja koji su predstavljali korpus na kome je izvršena analiza.

Prvo se pristupilo iščitavanju eseja i obeležavanju ograda i pojačivača prema definicijama datim u ranije obrazloženom korišćenom modelu metadiskursa (Hyland, 2005). Razvrstane su i same jezičke jedinice koje slabe, odnosno pojačavaju snagu iskaza, tj. gramatičke klase - glagoli, imenice, prilozi i pridevi. Pokazalo se da neke od njih vrše funkciju ograda, odnosno, pojačivača samostalno, a neke u okviru izraza. Podaci su zatim obrađeni kvantitativno. Pored dobijenih apsolutnih vrednosti za ograde i pojačivače u analiziranom korpusu, izračunate su i vrednosti normalizovane frekvencije (broj ograda/pojačivača na 1000 reči) kako bi se dobijeni rezultati lakše uporedili. Urađena je i analiza učestalosti upotrebe različitih vrsta reči upotrebljenih u funkciji odgovarajućih markera, kao i kratak osvrt na greške u upotrebi ograda i pojačivača u esejima. Rezultati sprovedenih analiza prikazani su u trećem odeljku i ilustrovani primerima iz korpusa koji su navedeni integralno.

\section{Rezultati istraživanja}

Analizirani korpus eseja broji ukupno 20.829 reči, što znači da je prosečna dužina eseja oko 168 reči. Utvrđeno je da je upotrebljeno 635 ograda i pojačivača ukupno (30,48 na 1000 reči). No, distribucija posmatranih metadiskursnih markera u korpusu nije ravnomerna, budući da varira od jednog upotrebljenog markera (7 eseja) do eseja gde je upotrebljeno ukupno 15 ovih markera (1 esej). Ukupan broj reči značajno je i pozitivno povezan sa ukupnim brojem korišćenih markera u eseju $(r=.25, p<.001)$. Što je duži napisani esej, tj. što više reči sadrži, to je veći broj korišćenih markera i obrnuto. 
Kada se pogledaju tipovi upotrebljenih markera, uočava se da su studenti u znatno većoj meri koristili ograde nego pojačivače prilikom iznošenja argumenata $u$ vezi sa zadatom temom. Na to nam ukazuje kako apsolutni broj upotrebljenih markera, 463 ograda prema 172 pojačivača, tako i normalizovana frekvencija: 22,23 upotrebljenih ograda na 1000 reči prema 8,26 pojačivača na 1000 reči (Grafikon I).

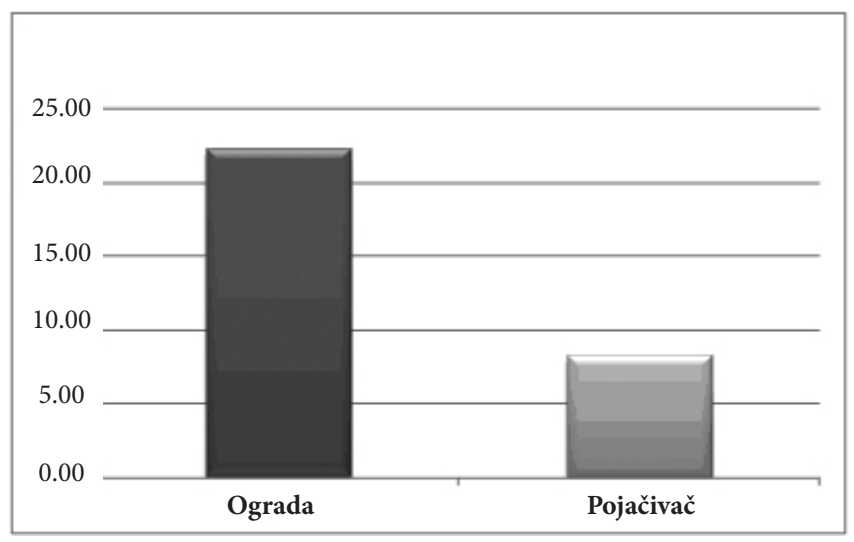

Grafikon I.

Broj ograda i pojačivača $u$ analiziranom korpusu (normalizovana frekvencija na 1000 reči)

Ukoliko imamo u vidu da se upotrebom ograda ublažavaju iznesene tvrdnje, odnosno, da se njima stavovi i razmišljanja predstavljaju pre kao pretpostavke i razne mogućnosti sa većom ili manjom verovatnoćom ostvarenja nego kao sigurne tvrdnje, ovakav nalaz nam ukazuje na to da studenti u oblikovanju argumenata ostavljaju dosta prostora čitaocu da formira stav, tj. da nisu skloni tome da nameću svoje mišljenje. S druge strane, s obzirom na to da su studenti eseje pisali u timu, očekivalo bi se da će svoje tvrdnje u većoj meri potkrepljivati pojačivačima, na taj način izražavajući sigurnost u zajedničke tvrdnje i razmišljanja, što ovde nije bio slučaj.

U pogledu adekvatnosti upotrebe, primećuje se da se često dešavalo da studenti iste ograde i pojačivače koriste više puta u tekstu. To naročito važi za ogradu in our/my opinion, koja je bila prisutna u gotovo svakom eseju, kao i za pojačivače I am sure that, really i of course. Zanimljivo je 
istaći da su studenti, iako je ovo bio grupni zadatak, veoma često koristili ličnu zamenicu prvog lica I (npr. I think that, I tend to use) ili prisvojni pridev my (npr. from my point of view, in my opinion, in my case).

\subsection{Upotreba ograda u analiziranom korpusu}

Kada se pogledaju vrste reči upotrebljene u funkciji ograda, uočavaju se glagolske pridevske, priloške i imeničke ograde. Učestalost njihove upotrebe $\mathrm{u}$ datom korpusu data je u Tabeli I.

Tabela I. Učestalost upotrebe leksičkih jedinica u funkciji ograda u analiziranom korpusu

\begin{tabular}{|l|c|c|}
\hline Gramatička klasa & Apsolutna frekvencija & $\begin{array}{c}\text { Normalizovana frekvencija } \\
\text { (na 1000 reči) }\end{array}$ \\
\hline Glagol & 272 & 13,06 \\
\hline Imenica & 79 & 3,79 \\
\hline Prilog & 100 & 4,80 \\
\hline Pridev & 12 & 0,58 \\
\hline Ukupno & $\mathbf{4 6 3}$ & $\mathbf{2 2 , 2 3}$ \\
\hline
\end{tabular}

Kao što se može videti u Tabeli I, prve po učestalosti upotrebe su glagolske ograde. Među njima, oko tri četvrtine čine modalni glagoli, naročito modali kao što su would i could (primeri 1 i 2). Takođe, kao ograde su se u manjoj meri upotrebljavali i leksički glagoli poput think, believe, imply, tend ili seem (primeri 3-5).

(1) Files could be sent using the Internet, payment could be done using credit cards.

(2) If all the books in the world were transfered into an electronic format, the books would be more accessible to more people.

(3) It seems it's very hard do it, but this world have many solutions.

(4) People tend to be oblivious and unappreciated of what they have.

(5) When we talk about older people, we think that this process would be also unsuccessful because they use cookers, fridges and many other electrical kitchen facilities.

Druge po učestalosti upotrebe, ali značajno manje korišćene nego glagolske ograde, jesu imeničke ograde, koje su najvećim delom zabeležene u varijacijama jednog izraza, in my/our opinion (primer 6). Takođe, 
korišćene su i imenice u okviru izraza in my case, from my point of view, from a personal standpoint i in this way (primeri 7-9).

(6) In our personal opinion lower household energy would be a very hard to manage, but also to take on food waste.

(7) We choose pledge 3 from a personal standpoint and considering this topic from a local point of view.

(8) In my case the hardest pledge to finish would be to try out a vegetarian recipe.

(9) So, from my point of view, it's very difficult, maybe impossible for someone to change the style of food.

Gotovo jednako učestalo kao i imeničke koriste se i priloške ograde. Neke od priloških ograda uočenih u korpusu obuhvataju maybe, probably, possibly, almost, approximately, about i generally (primeri 10-15).

(10) Maybe this isn't the real reason, it is just our opinion.

(11) In our opinion, the easiest pledge that can be possibly accomplished in the nearest future is the number 1 pledge.

(12) Generally speaking, people should spend more time playing sports, traveling, reading.

(13) Generally, people in Serbia often use public transport.

(14) Almost every household has a car and we would reduce carbon emissions by taking a bus or a train.

(15) Firstly, considering that electricity is responsible for nearly $40 \%$ of the global carbon footprint it is necessary to wake up human kind's self-awareness.

U okviru pridevskih ograda, u korpusu se najčešće sreću pridevi koji se javljaju u okviru konstrukcije it is possible to/that ili uz imenicu poput solution.

(16) But what can be a possible solution, apart from traditional cycling?

(17) It is possible to make paper without timber and water, without chlorine and acids, without waste, using only a third of the carbon footprint.

\subsection{Upotreba pojačivača u analiziranom korpusu}

Kao i u slučaju ograda, kada se radi o vrstama reči u funkciji određenog diskursnog markera, postoje primeri za priloške, glagolske, pridevske 
UPOTREBA OGRADA I POJAČIVAČA U STUDENTSKIM ESEJIMA O ZAŠTITI ...

i imeničke pojačivače. Učestalost njihovog javljanja u korpusu data je u Tabeli II. Za razliku od ograda, u korpusu se kao pojačivači ubedljivo najčešće koriste prilozi.

Tabela II.

Učestalost upotrebe leksičkih jedinica u funkciji pojačivača u analiziranom korpusu

\begin{tabular}{|l|c|c|}
\hline Gramatička klasa & Apsolutna frekvencija & $\begin{array}{c}\text { Normalizovana frekvencija } \\
\text { (na 1000 reči) }\end{array}$ \\
\hline Prilog & 96 & 4,61 \\
\hline Glagol & 63 & 3,02 \\
\hline Imenica & 8 & 0,38 \\
\hline Pridev & 5 & 0,24 \\
\hline Ukupno & $\mathbf{1 7 2}$ & $\mathbf{8 , 2 6}$ \\
\hline
\end{tabular}

Postoji širok opseg priloških pojačivača pronađenih u korpusu, kao što su obviously, certainly, of course, completely, significantly, really, actually ili definitely. Neki od primera iz eseja u kojima su ovi pojačivači upotrebljeni dati su u nastavku (18-22).

(18) In our opinion, the easiest pledge to accomplish is certainly the pledge number 3 .

(19) In general I think that most difficult pledge would be to try new vegetarian recipe, because people think that meat is healthy and essential, but really it is not.

(20) Actually there is one energy source which is in a great rise.

(21) Of course this wouldn't be a problem, if electricity was generated from renewable sources [...].

(22) Lowering my household electricity use would definitely be the easiest.

Sledeći po učestalosti jesu glagolski pojačivači (primeri 23-26). U korpusu se najčešće javlja glagol will (koji je, ukupno gledano, najčešće korišćena leksema u funkciji pojačivača) i leksički glagol know.

(23) If we keep going like this, we will lose everything, so it is better to prevent than to heal, because in this case there is no medicine.

(24) If carbon emissions continue further, the ecosystem will get seriously damaged and natural disasters will start happening more often.

(25) As we all know our city is proclaimed as the most polluted city in Europe. 
Tijana S. Vesić Pavlović / Danijela D. Đorđević

(26) So when our will power is not so strong it is easier for us to go back to eating meat because we know that nobody will judge us and to them you will come back to normal.

Imenički i pridevski pojačivači javili su se u veoma malom broju $\mathrm{u}$ analiziranim esejima. U funkciji imeničkog pojačivača je upotrebljena samo jedna imenica, fact, i to sama ili u izrazima (primeri 27, 28), dok je među pridevskim pojačivačima najčešći izraz I am sure (that), kao i pridevi obvious i certain (primeri 29-31).

(27) This is also due to the fact that is the most inexpensive way of commuting.

(28) It is a fact that most of paper comes from trees, and trees are essential for our survival.

(29) We don't have any other logical explanation for vegetarians, if they only know the combinations of flavours with meat and vegetables, they wouldn't be vegetarians, I am sure.

(30) Because of the all of these positive reasons, we are certain that this is the easiest and also the most important pledge that we should all accomplish on a regular basis.

(31) To conclude, from everything we mentioned before it is obvious that accomplishing this pledge is much easier than accomplishing other pledges because it acquires minimal effort.

\section{Diskusija i zaključna razmatranja}

Predmet ovog istraživanja bio je da se ispita upotreba dve skupine metadiskursnih markera - ograda i pojačivača - u esejima timova studenata napisanih na temu sprečavanja efekata globalnog zagrevanja i ličnih napora da se zaštiti životna sredina. Rezultati pokazuju da studenti koriste obe grupe metadiskursnih markera, ali ne u podjednakoj meri - ograde su daleko frekventnije nego pojačivači u analiziranom korpusu eseja. U okviru obe klase posmatranih metadiskursnih markera, studenti su upotrebljavali različite vrste reči da ih izraze (glagole, imenice, prideve, priloge).

Frekvencija upotrebe posmatranih metadiskursnih markera u analiziranom korpusu, naročito ograda, govori nam da je stepen fluentnosti studenata u pogledu akademskog pisanja na engleskom jeziku adekvatan, kao i njihova sposobnost da koriste metadiskursne markere. Međutim, treba imati u vidu da su studenti eseje pisali u timovima, što je moglo značajno 
da utiče na sam kvalitet eseja i kvalitet upotrebljenog jezika. Takođe, podrobnija analiza konteksta u kojima su upotrebljavane ograde i pojačivači otkriva nam da postoji mogućnost za poboljšanje. Činjenica da su se iste ograde i pojačivači po nekoliko puta ponavljali u okviru jednog istog eseja (npr. in my/our opinion, would, will, really) ukazuje na to da studenti nisu dovoljno obraćali pažnju na to na koji način ih treba koristiti, pa je tako ponavljanje istih reči ili izraza moglo ostaviti loš utisak na čitaoca i donekle poremetiti praćenje teksta.

Ovakav nalaz u skladu je sa nalazima ranijih istraživanja o tome koliko studenti upotrebljavaju ograde, a koliko pojačivače u argumentativnim esejima (npr. Crompton, 2012; Lee \& Deakin, 2016). To što su studenti u znatno većoj meri upotrebljavali ograde može se povezati sa stepenom sigurnosti koji su timovi studenata imali u tvrdnje koje su iznosili. Naime, s obzirom na to da je u ovom tipu zadatka cilj autora teksta bio da ubede svoju publiku u istinitost određene tvrdnje, njihova sigurnost $u$ iskaz uticala je na to hoće li upotrebiti ograde ili pojačivače. Kod onih tvrdnji u koje su bili sigurniji, studenti su koristili prvi tip uslovnih rečenica, a tamo gde su želeli da pokažu veći stepen suzdržanosti upotrebljavali su uslovne rečenice drugog tipa. Studenti su verovatno kao čitaoca eseja pre svega videli nastavnika, tako da su ostavljali prostora za pregovaranje, odnosno, da se njihovi argumenti pre protumače kao moguća rešenja i promišljanja, a ne kao sigurno razrešenje datog problema, bez obzira na činjenicu da su radili kao tim i izražavali timsko mišljenje. Otuda možda i tentativni ton, koji, opet, predstavlja važno persuazivno sredstvo.

Rezultati ovog istraživanja iznova ukazuju na potrebu da se studentima na eksplicitan način ukaže na značaj pravilne upotrebe metadiskursnih markera, naročito ograda i pojačivača, kako bi bili sposobni da adekvatno prenesu svoje ideje u tekstu na engleskom jeziku. Kao što je već istaknuto u ranijim istraživanjima, ,kada se ograde koriste na adekvatan način, podižu etički nivo teksta jer oni koji tekst pišu moraju da promisle o stvarima za koje veruju da su istinite i na koji način treba da potkrepe te dokaze" (Intaraprawat \& Steffensen, 1995: 267). Takođe, po ugledu na prethodne studije (Hyland, 2000), trebalo bi sprovesti istraživanje o tome u kojoj meri studenti mogu da prepoznaju ograde i pojačivače u tekstovima, koje bi moglo da pruži uvide u to da li oni ove diskursne markere koriste na osnovu predznanja ili ih mahom upotrebljavaju po osećaju, što dovodi i do neadekvatne upotrebe. 
Tijana S. Vesić Pavlović / Danijela D. Đorđević

\section{LITERATURA}

Blagojević, S. (2008). Metadiskurs u akademskom diskursu. Niš: Filozofski fakultet.

Ceković-Rakonjac, N. (2011). Različiti pristupi definisanju i opisu diskursnih markera. Anali Filološkog fakulteta, 23(2), 133-153.

Cheng, X. \& Steffensen, M. S. (1996). Metadiscourse: A technique for improving student writing. Research in the Teaching of English, 30(2), 149-181.

Crismore, A. (1983). Metadiscourse: What it is and How it is Used in School and Non-school Social Science Texts. Illinois: University of Illinois, Centre for the Study of Reading.

Crismore, A., Markkanen, R. \& Steffensen, M. S. (1993). Metadiscourse in persuasive writing: A study of texts written by American and Finnish university students. Written communication, 10(1), 39-71.

Crompton, P. (2012). Characterising Hedging in Undergraduate Essays by Middle Eastern Students. The Asian ESP Journal, 8(2), 55-78.

Đorđević, D. (2015). Priloške ograde u naučnim radovima na engleskom i srpskom jeziku. Nasleđe, XII(31), 215-230.

Đorđević, D. (2017a). Epistemic modality markers used as hedges in research articles. Belgrade English Language \& Literature Studies, IX, 25-47.

Đorđević, D. (2017b). Ograde u naučnim radovima na engleskom i srpskom jezi$k u$ (neobjavljena doktorska disertacija). Filološki fakultet, Beograd.

Fraser, B. (2010). Pragmatic Competence: The Case of Hedging. In G. Kaltenböck, W. Mihatsch, \& S. Schneider (Eds.), New Approaches to Hedging (pp. 15-34). Bingley: Emerald Group Publishing Limited.

Ho, V. \& Li, C. (2018). The use of metadiscourse and persuasion: An analysis of first year university students' timed argumentative essays. Journal of English for Academic Purposes, 33, 53-68.

Holmes, J. (1982). Expressing Doubt and Certainty in English. RELC Journal, 13(2), 9-28.

Holmes, J. (1984). Modifying illocutionary force. Journal of Pragmatics, 8(3), $345-365$.

Holmes, J. (1988). Doubt and certainty in ESL textbooks. Applied Linguistics, $9(1), 21-44$.

Holmes, J. (1990). Hedges and boosters in women's and men's speech. Language and Communication, 10(3), 185-205.

Hu, G., \& Cao, F. (2011). Hedging and boosting in abstracts of applied linguistics articles: A comparative study of English and Chinese-medium journals. Journal of Pragmatics, 43(11), 2795-2809. 
Hyland, K. \& Tse, P. (2004). Metadiscourse in academic writing: A Reappraisal. Applied Linguistics, 25(2), 156-177.

Hyland, K. (1998). Hedging in Scientific Research Articles. Amsterdam: John Benjamins.

Hyland, K. (2000). Hedges, boosters and lexical invisibility: Noticing modifiers in academic texts. Language Awareness, 9(4), 179-197.

Hyland, K. (2005). Metadiscourse: Exploring Interaction in Writing. London/ New York: Continuum.

Hyland, K. (2017). Metadiscourse: What is it and where is it going? Journal of Pragmatics, 113, 16-29.

Intaraprawat, P. \& Steffensen, M. (1995). The use of metadiscourse in good and poor ESL essays. Journal of Second Language Writing, 4(3), 253-272.

Lakoff, G. (1973). Hedges: A study in meaning criteria and the logic of fuzzy concepts. Journal of Philosophical Logic, 2(4), 458-508.

Lee, J. J. \& Deakin, L. (2016). Interactions in L1 and L2 undergraduate student writing: Interactional metadiscourse in successful and less-successful argumentative essays. Journal of Second Language Writing, 33, 21-34.

Lee, J. J. \& Casal, J. E. (2014). Metadiscourse in results and discussion chapters: A cross-linguistic analysis of English and Spanish thesis writers in engineering. System, 46, 39-54.

Li, T. \& Wharton, S. (2012). Metadiscourse repertoire of L1 Mandarin undergraduates writing in English: A cross-contextual, cross-disciplinary study. Journal of English for Academic Purposes, 11(4), 345-356.

Steffensen, M. S. \& Cheng, X. (1996). Metadiscourse and Text Pragmatics: How Students Write After Learning about Metadiscourse. Pragmatics and Language Learning, 7, 1-18.

Vande Kopple, W. (1985). Some exploratory discourse on metadiscourse. College Composition and Communication, 36, 82-93.

Vande Kopple, W. (2012). The importance of studying metadiscourse. Applied Research in English, 1(2), 37-44.

Yang, W. \& Sun, Y. (2012). The use of cohesive devices in argumentative writing by Chinese EFL learners at different proficiency levels. Linguistics and Education, 23(1), 31-48. 


\title{
Tijana Vesić Pavlović
}

Danijela Đorđević

\section{THE USE OF HEDGES AND BOOSTERS IN STUDENTS' ESSAYS ON ENVIRONMENTAL PROTECTION WRITTEN IN ENGLISH}

\begin{abstract}
Summary
In recent years, the use of metadiscourse in the material written at the university level of language learning has been a very important topic in the literature. This paper deals with the use of two specific metadiscourse features, hedges and boosters, in students' essays related to the issues of preventing the effects of global warming. The essays were produced during a university-level English language course at the Faculty of Mechanical Engineering. A total of 124 essays (20,829 words) were analysed. Using Hyland's interpersonal metadiscourse model, it was found that hedges were much more frequent in the analysed essays in comparison to boosters ( 22.23 vs. 8.26 per 1000 words). Within both classes, there were examples of use of different verbs, nouns, adverbs, and adjectives acting as hedges or boosters. The conclusion points to the need to introduce metadiscourse markers in the curriculum of foreign language teaching at the university level, given their importance not only in academic but also in other types of texts that (graduate) students will deal with both during and after their studies.
\end{abstract}

Key words: metadiscourse, hedges, boosters, students' essays, English. 